\title{
FAKTOR - FAKTOR YANG BERHUBUNGAN KEJADIAN OBESITAS PADA WANITA USIA SUBUR (WUS) DI WILAYAH KERJA PUSKESMAS LEPO - LEPO
}

\author{
${ }^{*}$ Apriyanti ${ }^{1}$, Tasnim ${ }^{1}$, Kartini ${ }^{2}$ \\ ${ }^{1}$ STIKES Mandala Waluya Kendari, ${ }^{2}$ Poltekkes Depkes RI, *aisyahapril280@gmail.com
}

\section{INFO ARTIKEL}

Riwayat Artikel:

Diterima: 09-06-2019

Disetujui: 20-01-2020

\section{Kata Kunci:}

Obesitas Wanita Usia Subur

Kontrasepsi

Pola Makan

Indeks massa tubuh Gizi

\begin{abstract}
ABSTRAK
Abstrak: Obesitas merupakan salah satu permasalahan gizi yang banyak dijumpai pada golongan masyarakat dengan sosial ekonomi menengah keatas. Makhluk hidup akan mencapai keseimbangan jika energi yang masuk sama dengan energi yang dikeluarkan. Menurut WHO (2000), seseorang dikatakan obesitas jika nilai Indeks Massa Tubuh (IMT) diatas $30,0 \mathrm{~kg} / \mathrm{m} 2$.Sedangkan IMT antara $25-29,9 \mathrm{~kg} / \mathrm{m} 2$ disebut pre obesitas. Untuk orang Asia, IMT diatas $25 \mathrm{~kg} / \mathrm{m} 2$ termasuk obesitas. Fenomena ini juga terjadi di Kota Kendari tercatat, pada tahun 2015 jumlah penderita obesitas yang ditemukan sebesar 698 orang dengan penderita terbanyak berada di wilayah kerja Puskesmas Lepo - Lepo. Tahun 2016 jumlah penderita yang ditemukan meningkat menjadi 1344 orang dengan penderita terbanyak yang ditemukan di wilayah kerja Puskesmas Mandonga dan Lepo- Lepo. Penelitian ini bertujuan untuk menganalisis faktor-faktor yang berhubungan dengan kejadian obesitas pada wanita usia subur (WUS) di wilayah kerja Puskesmas Lepo Lepo Kota Kendari. Jenis Penelitian Yang di gunakan adalah kuantitatif, dengan pendekatan cross sectional study. Populasi dalam penelitian adalah wanita usia subur (WUS) yang menggunakan alat kontrasepsi berjumlah 2591 orang. Sampel dalam penelitian ini adalah sebanyak 69 responden Hasil penelitian menunjukkan ada hubungan yang bermakna antara penggunaan kontrasepsi hormonal dengan kejaidian obesitas dengan koefien Phi 0,477 (kategori sefang). Terdapat hubungan antara lama penggunaan kontrasepsi dengan kejadian obesitas dengan nilai koefisien phi 0,42 (sedang), terdapat hubungan antara pola makan dengan obesitas koefisien phi 0,62 (kuat).
\end{abstract}

\begin{abstract}
Obesity is one of the nutritional problems that are often found in groups of people with middle and upper socioeconomic groups. Living things will reach a balance if the incoming energy is the same as the energy expended. According to WHO (2000), a person is said to be obese if the value of the Body Mass Index (BMI) is above $30.0 \mathrm{~kg} / \mathrm{m}^{2}$. While the BMI is between $25-29.9 \mathrm{~kg} / \mathrm{m}^{2}$ is called pre obesity. For Asians, BMI above 25 $\mathrm{kg} / \mathrm{m}^{2}$ including obesity. This phenomenon also occurred in the city of Kendari, recorded in 2015 the number of obese people found was 698 people with the most patients in the working area of the Lepo - Lepo Health Center. In 2016 the number of patients found increased to 1344 with the most patients found in the working area of the Mandonga and Lepo-Lepo Puskesmas. This study aims to analyze the factors associated with the incidence of obesity in women of childbearing age (WUS) in the work area of the Lepo Lepo Health Center in Kendari City. The type of research used is quantitative, with a cross sectional study approach. The population in the study were women of childbearing age (WUS) who used contraception totaling 2591 people. The sample in this study were 69 respondents. The results showed there was a significant relationship between the use of hormonal contraception and obesity status with the coefficient Phi 0.477 (sefang category). There is a relationship between the length of use of contraception with the incidence of obesity with a coefficient value of phi 0.42 (moderate), there is a relationship between diet and obesity a phi coefficient of 0.62 (strong).
\end{abstract}

\section{A. LATAR BELAKANG}

Obesitas merupakan salah satu permasalahan gizi yang banyak dijumpai pada golongan masyarakat dengan sosial ekonomi menengah keatas. Makhluk hidup akan mencapai keseimbangan jika energi yang masuk sama dengan energi yang dikeluarkan (Waspadji, 2010).
Menurut WHO (2000), seseorang dikatakan obesitas jika nilai Indeks Massa Tubuh (IMT) diatas 30,0 $\mathrm{kg} / \mathrm{m} 2$.Sedangkan IMT antara $25-29,9 \mathrm{~kg} / \mathrm{m} 2$ disebut pre obesitas.Untuk orang Asia, IMT diatas $25 \mathrm{~kg} / \mathrm{m} 2$ termasuk obesitas. Obesitas saat ini menjadi permasalahan dunia bahkan Organisasi Kesehatan Dunia (WHO) mendeklarasikan sebagai Penyakit global 
(Swandari et al., 2017). Menurut Organisasi Kesehatan Dunia atau World Health Organization (WHO) pada tahun 2016, 18\% anak - anak dan remaja usia 5-19 tahun mengalami berat badan lebih atau obese. Dari data tersebut juga diketahui bahwa $39 \%$ wanita dan $39 \%$ pria usia 18 tahun ke atas mengalami berat badan lebih (WHO, 2017).

Berdasarkan data WHO dapat diketahui bahwa obesitas merupakan masalah Penyakit global yang menjadi ancaman serius bagi kesehatan masyarakat di dunia, sebesar 2,8 juta orang meninggal karena penyakit seperti diabetes dan penyakit jantung sebagai akibat dari obesitas (WHO, 2017). Hal ini sejalan dengan penelitian yang dilakukan dengan melakukan pemantauan berkala perubahan prevalensi kelebihan berat badan dan obesitas pada semua populasi di dunia dari tahun 1980 hingga 2013 menunjukkan penderita obesitas di Eropa Barat sebanyak 13,9\%. Prevalensi obesitas tertinggi yaitu di Uruguay (18,1\%), Costa Rica (12,4\%), Chili (11,9\%) dan Meksiko (10,5\%) (Pratiwi et al., 2018). Di Indonesia sendiri, sebanyak 40 juta orang dewasa mengalami kegemukan, dan Indonesia masuk ke peringkat 10 daftar negara-negara seperti yaitu Jepang berkisar 23,2 \%, Amerika Serikat berkisar 66,3 \%, arab Saudi berkisar 35,6 \%,Cina berkisar 3,7\%, Korea Selatan berkisar 2,4 \%, Eropa berkisar 20,7 \%, Australia berkisar 25,1\%, kanada berkisar 24,3\%, Bahrain 32,6\%, dan Brazil 19,5\%.dengan tingkat obesitas terbanyak di dunia. Orang yang mengalami obesitas berada pada risiko yang lebih tinggi untuk penyakit yang serius seperti tekanan darah tinggi, serangan jantung, stroke, diabetes, penyakit kandung empedu, dan kanker.Risiko pada orang yang mengalami obesitas beberapa kali lebih tinggi dari orang-orang yang memiliki berat badan yang sehat dan normal (KemenKes RI, 2018).

Data hasil Riset Kesehatan Dasar (Riskesdas) pada tahun 2007, 2013 dan 2018, menunjukkan terjadinya peningkatan proporsi berat badan lebih dan obese pada usia $>18$ tahun dari waktu ke waktu. Proporsi berat badan lebih (over weight) pada riskesdas tahun 2007 sebesar 8,6\%, tahun 2013 meningkat menjadi 11,5\% dan tahun 2018 meningkat menjadi 13,8\%.Untuk proporsi obese pada saat Riskesdas 2007 sebesar 10,5\%, tahun 2013 mengalami peningkatan sebesar 14,8\% dan tahun 2018 mengalami peningkatan menjadi sebesar 21,8\%. Sedangkan pada kategori obesitas sentral pada usia $\geq 15$ tahun juga menunjukkan peningkatan dari waktu ke waktu, tercatat tahun 2013 proporsi obesitas sentral sebesar 18,8\%, tahun 2013 sebesar 26,6\% dan tahun 2018 sebesar 31\% (Riskesdas, 2018).

Fenomena ini juga terjadi di Kota Kendari tercatat, pada tahun 2015 jumlah penderita obesitas yang ditemukan sebesar 698 orang dengan penderita terbanyak berada di wilayah kerja Puskesmas Lepo Lepo. Tahun 2016 jumlah penderita yang ditemukan meningkat menjadi 1344 orang dengan penderita terbanyak yang ditemukan di wilayah kerja Puskesmas
Mandonga dan Lepo- Lepo. Pada tahun 2017 meningkat lagi menjadi sebesar 2.919 orang dengan jumlah penderita terbanyak yang ditemukan diwilayah kerja Puskesmas Lepo-Lepo (Dinas Kesehatan Kota Kendari, 2018).

\section{B. METODE PENELITIAN}

Jenis penelitian ini adalah penelitian kuantitatif, dengan pendekatan cross sectional study, yang bertujuan untuk mengetahui hubungan antara variabel bebas (jenis kontrasepsi, lama penggunaan kontrasepsi, pola makan,aktivitas fisik,riwayat keluarga) dengan variabel terikat (obesitas), Artinya antara variabel bebas dengan variabel terikat diobservasi sekaligus pada saat yang sama (Notoatmodjo S, 2014). Populasi dalam penelitian adalah wanita usia subur (WUS) yang menggunakan alat kontrasepsi berjumlah 2591 orang. Teknik pengambilan sampel dalam penelitian ini menggunakan simple random sampling atau teknik pengambilan sampel secara acak sederhana dimana setiap anggota atau unit dari populasi mempunyai kesempatan yang sama untuk diseleksi sebagai sampel. Pengambilan sampel secara acak sederhana ini dilakukan dengan mengundi anggota populasi (lottery technique) atau teknik undian. Jumlah sampel sebanyak 69 responden.

\section{HASIL DAN PEMBAHASAN}

\section{Hubungan antara jenis kontrasepsi dengan kejadian obesitas.}

\section{Hubungan antara jenis kontrasepsi dengan kejadian obesitas}

\begin{tabular}{|c|c|c|c|c|c|c|c|}
\hline \multirow{3}{*}{$\begin{array}{c}\text { Lama } \\
\text { Penggunaan } \\
\text { Kontrasepsi }\end{array}$} & \multicolumn{4}{|c|}{ Kejadian Obesitas } & \multirow{2}{*}{\multicolumn{2}{|c|}{ Jumlah }} & \multirow{2}{*}{ phi } \\
\hline & \multicolumn{2}{|c|}{ Obesitas } & \multicolumn{2}{|c|}{$\begin{array}{c}\text { Tidak } \\
\text { Obesitas }\end{array}$} & & & \\
\hline & $\mathbf{n}$ & $\%$ & $\mathbf{n}$ & $\%$ & $\mathbf{n}$ & $\%$ & \\
\hline $\begin{array}{c}\text { Berisiko } \\
\text { Tidak }\end{array}$ & 32 & 70 & 14 & 30 & 46 & $100 \%$ & 0,412 \\
\hline Berisiko & 6 & 26 & 17 & 74 & 23 & $100 \%$ & \\
\hline Jumlah & 38 & 55 & 31 & 45 & 69 & $100 \%$ & \\
\hline
\end{tabular}

Hasil uji keeratan hubungan menunjukkan koefisienPhi $(\Phi)$ sebesar 0,477, hal ini menunjukkan kekuatan hubungan antara antara jenis kontrasepsi dengan kejadian obesitas di Puskesmas Lepo-Lepo kategori hubungan sedang.

Seperti diketahui bahwa Gonadal steroid hormone (GSH), dalam hal ini androgen, estrogen dan progestin meru - pakan molekul yang pluripoten signaling dengan aktivitas biologi yang bervariasi yang kebanyakan daripadanya tidak jelas hubungan antara fungsi primer reproduksi dengan hipothalamo - pituitary gonadal axis (HPG -axis). GSH berpengaruh secara independen terhadap 
kenaikan berat badan dan makan makanan lemak, termasuk juga terhadap energy expenditor dan fungsi saluran cerna, metabolisme, pertumbuhan dan komposisi tubuh.HPG axis mempunyai efek secara hirarki yaitu: (i) hypothalamic releasing hormone GnRH (atau LHRH), yang mensintesis sel- sel neuron al bodies yang terletak pada nucleus arkuata area preoptik, (ii) hormon pituitary anterior, FSH dan LH, (iii) gonadal hormon, testosteron, estrogen dan progesteron yang bekerja pada sejum - lah jaringan target. Masing - masing bertin - dak sebagai control feedback terhadap fungsi HPG melalui reseptor hipthalamus dan pituitary.

Pada penelitian yang dilakukan oleh T.Lee, et al (2014) memperlihatkan kenaikan berat badan secara signifikan dengan penggunaan kontrasepsi depot medroxy progesterone asetat (DMPA). Kenaikan berat bedan terjadi berkisar 3,0 kg selama 12 bulan hingga 9,4 kg selama 18 bulan. Penelitian tersebut hanya berfokus pada kenaikan berat badan. Seperti diketahui bahwa Gonadal steroid hormone (GSH), dalam hal ini androgen, estrogen dan progestin merupakan molekul yang pluripoten signaling dengan aktivitas biologi yang bervariasi yang kebanyakan daripadanya tidak jelas hubungan antara fungsi $\mathrm{p}$ rimer reproduksi dengan hipothalamo -pituitary gonadal axis (HPGaxis).Namun pada penelitian ini tidak diperinci jenis kontrasepsi hormonal yang digunakan dengan sampel 77 orang serta pola kenaikan berat badan.

\section{Hubungan antara lama penggunaan} kontrasepsi dengan kejadian obesitas

TABEL 2.

Hubungan antara Lama Penggunaan kontrasepsi dengan kejadian obesitas

\begin{tabular}{|c|c|c|c|c|c|c|c|}
\hline \multirow{3}{*}{$\begin{array}{c}\text { Pola } \\
\text { Makan }\end{array}$} & \multicolumn{4}{|c|}{ Kejadian Obesitas } & \multirow{2}{*}{\multicolumn{2}{|c|}{ Jumlah }} & \multirow[b]{2}{*}{ phi } \\
\hline & \multicolumn{2}{|c|}{ Obesitas } & \multicolumn{2}{|c|}{$\begin{array}{c}\text { Tidak } \\
\text { Obesitas }\end{array}$} & & & \\
\hline & $\mathbf{n}$ & $\%$ & $\mathbf{n}$ & $\%$ & $\mathbf{n}$ & $\%$ & \multirow{4}{*}{0,620} \\
\hline Kurang & 34 & 79 & 9 & 21 & 43 & $100 \%$ & \\
\hline Baik & 4 & 15 & 22 & 85 & 26 & $100 \%$ & \\
\hline Jumlah & 38 & 55 & 31 & 45 & 69 & $100 \%$ & \\
\hline
\end{tabular}

Hasil uji keeratan hubungan menunjukkan koefisienPhi $(\Phi)$ sebesar 0,412, hal ini menunjukkan kekuatan hubungan antara antara lama penggunaan dengan kejadian obesitas di Puskesmas Lepo-Lepo kategori hubungan sedang.

Obesitas banyak dialami oleh akseptor DMPA yang telah menggunakan DMPA selama 18 bulan, dibandingkan pemakaian selama 6 bulan dan 12 bulan. Pada pemakaian DMPA selama 18 bulan, $19 \%$ akseptor mengalami obesitas. Sedangkan pemakaian selama 12 bulan sebanyak 9,7\% akseptor mengalami obesitas, dan pemakaian selama 6 bulan hanya 4,6\% akseptor yang mengalami obesitas.
Angka obesitas yang semakin meningkat berkaitan dengan peningkatan berat badan yang semakin besar seiring lamanya penggunaan DMPA. Laporan WHO seperti yang dikutip oleh Cunningham mengemukakan, terjadi peningkatan berat badan rata-rata sebesar 2,7 $\mathrm{kg}$ pada tahun pertama pemakaian DMPA, $4 \mathrm{~kg}$ setelah 2 tahun, dan $7 \mathrm{~kg}$ setelah 3 tahun pemakaian. Terjadi peningkatan berat badan sebesar $0,5 \mathrm{~kg}$ pada 3 bulan pertama pemakaian DMPA, $1 \mathrm{~kg}$ setelah 6 bulan pemakaian, dan $1,7 \mathrm{~kg}$ setelah 12 bulan pemakaian. (15) Sementara penelitian yang dilakukan oleh Purnamasari melaporkan, sebanyak 10\% akseptor dengan lama pemakaian kontrasepsi DMPA 1-3 tahun mengalami kenaikan berat badan, akseptor yang lama pemakaian kontrasepsi DMPA 3-4 tahun sebanyak 16,66\% mengalami kenaikan berat badan, sedangkan akseptor yang lama pemakaian kontrasepsi DMPA >4 tahun sebanyak 46,67\% mengalami kenaikan berat badan. Hal ini menunjukkan terdapat hubungan antara lama penggunaan kontrasepsi DMPA dengan peningkatan berat badan, dimana keadaan ini menyebabkan risiko obesitas pada penggunaan kontrasepsi DMPA semakin meningkat seiring lamanya penggunaan.

\section{Hubungan antara pola makan dengan kejadian obesitas}

TABEL 3.

Hubungan antara pola makan dengan kejadian obesitas

\begin{tabular}{|c|c|c|c|c|c|c|c|}
\hline \multirow{3}{*}{$\begin{array}{l}\text { Lama } \\
\text { Penggunaan } \\
\text { Kontrasepsi }\end{array}$} & \multicolumn{4}{|c|}{ Kejadian Obesitas } & \multirow{2}{*}{\multicolumn{2}{|c|}{ Jumlah }} & \multirow{2}{*}{ phi } \\
\hline & \multicolumn{2}{|c|}{ Obesitas } & \multicolumn{2}{|c|}{$\begin{array}{c}\text { Tidak } \\
\text { Obesitas }\end{array}$} & & & \\
\hline & $\mathbf{n}$ & $\%$ & $\mathbf{n}$ & $\%$ & $\mathbf{n}$ & $\%$ & \\
\hline $\begin{array}{c}\text { Berisiko } \\
\text { Tidak }\end{array}$ & 32 & 70 & 14 & 30 & 46 & $100 \%$ & 0,412 \\
\hline Berisiko & 6 & 26 & 17 & 74 & 23 & $100 \%$ & \\
\hline Jumlah & 38 & 55 & 31 & 45 & 69 & $100 \%$ & \\
\hline
\end{tabular}

Hasil uji keeratan hubungan menunjukkan koefisienPhi( $\Phi)$ sebesar 0,620 , hal ini menunjukkan kekuatan hubungan antara antara pola makan dengan kejadian obesitas di Puskesmas Lepo-Lepo kategori hubungan kuat. Pola makan adalah berbagai informasi yang memberikan gambaran mengenai macam dan jumlah bahan makanan yang dimakan setiap hari oleh satu orang dan merupakan cirri khas untuk suatu kelompok masyarakat tertentu Keterangan ini dapat diperoleh melalui suatu pendataan yang dikenal sebagai survey diet, yang umumya merupakan sebagian dari suatu kegiatan pengumpulan data yang lebih komprehensip, yaitu survey gizi masyarakat. 


\section{SIMPULAN DAN SARAN}

1. Simpulan

a. Terdapat hubungan Sedang antara jenis kontrasepsi dengan kejadian obesitas Pada Pasangan Usia Subur di Wilayah Kerja Puskesmas Lepo-Lepo

b. Terdapat hubungan Sedang antara lama penggunaan dengan kejadian obesitas Pada Pasangan Usia Subur di Wilayah Kerja Puskesmas Lepo-Lepo

c. Terdapat hubungan Kuat antara pola makan dengan kejadian obesitas Pada Pasangan Usia Subur di Wilayah Kerja Puskesmas Lepo-Lepo.

2. Saran

Tenaga medis hendaknya memberikan pelayanan dan edukasi yang baik kepada calon akseptor kontrasepsi DMPA tentang efek samping penggunaan DMPA dalam jangka waktu yang lama. Akseptor kontrasepsi DMPA hendaknya dapat melakukan skrining terhadap penyakit yang dapat timbul akibat peningkatan berat badan seperti penyakit kardiovaskular maupun dibetes mellitus. Selain itu setiap akseptor kontrasepsi DMPA hendaknya berolahraga secara rutin serta menjaga pola makan untuk menjaga berat badan.

\section{DAFTAR RUJUKAN}

[1] DINAS KESEHATAN KOTA KENDARI 2018. Profil Kesehatan Kota Kendari 2017. Kendari: Dinkes.

[2] DINAS KESEHATAN PROVINSI SULAWESI TENGGARA 2018. Profil Kesehatan Selawesi Tenggara Tahun 2017. Sulawesi Tenggara: Dinkes Sultra.

[3] KEMENKES RI 2018. Profil kesehatan Indonesia tahun 2017. Jakarta: Kementerian Kesehatan Republik Indonesia.

[4] NOTOATMODJO S 2014. Metode Penelitian Kesehatan. Jakarta. Rineka Cipta.

[5] PUSKESMAS LEPO-LEPO 2018. Profil Puskesmas LepoLepo. Kendari:Puskesmas Lepo-Lepo.

[6] RAHMATULLAH, P. \& LOLO, J. 2010. Faal Paru pada Obesitas. MajalahKedokteranIndonesia.

[7] RISKESDAS 2018. Laporan hasil riset Nasional. RISKESDAS.

[8] SYARIF, D. R. Childhood obesity: Evaluation and management. Surabaya: Naskah Lengkap National Obesity Symposium II, 2003. 155-170.

[9] WASPADJI, S. 2010. Daftar Bahan Makanan Penukar Edisi 3. Jakarta : Badan Penerbit FK UI.

[10] WHO 2017. Obesity. World Health Organization.

[11] T. Lee, H. Lee, H. M. Ahn, Y. Jang, H. Shin, and M. S. Kim, "Perceptions about family planning and contraceptive practice in a marital dyad," J Clin Nurs, vol. 23, no. 7-8, pp. 1086-1094, Apr. 2014.

\section{PROFIL PENULIS UTAMA}

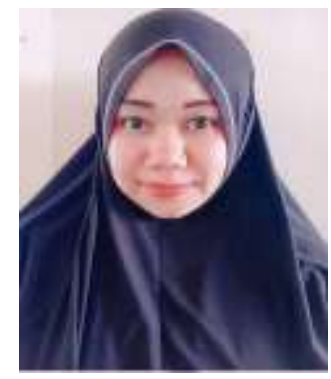

Apriyanti

S1 Keperawatan STIKES Mandala Waluya Kendari

Profesi Ners STIKES Mandala Waluya

Kendari 